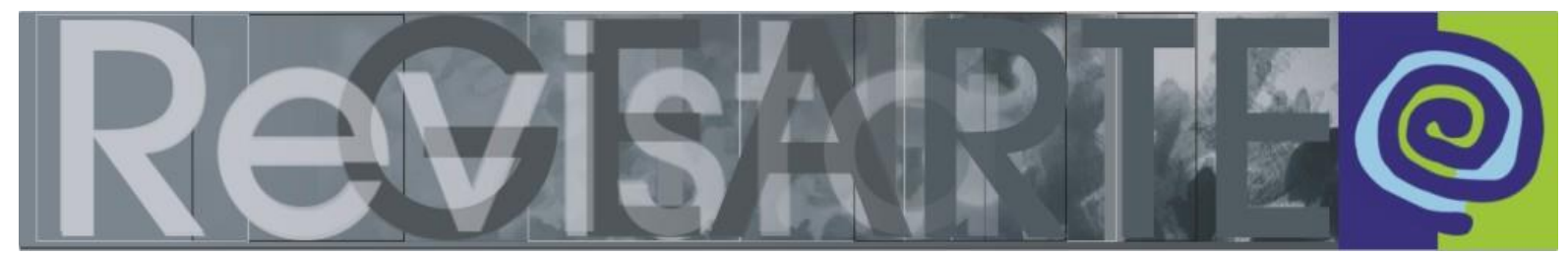

ISSN 2357-9854 | e-ISSN 2596-3198 (online)

\title{
La enseñanza de las artes visuales y la artesanía: experiencias, confluencias y derivas
}

El contenido que presenta esta edición de la Revista GEARTE se inscribe en una genealogía que atraviesa buena parte de la jerarquización que ha articulado algunas de las dualidades dominantes en las artes, como práctica profesional y en la educación que se vincula con las artes: artes mayores y menores, alta y baja cultura, educación artística y artesanía, facultades de bellas artes y escuelas de artes y oficios, cultura popular y cultura artística, etc. Lo que lleva a Freitag (2015) al reseñar la obra de Shiner (2004), a apuntar una distinción muy marcada entre lo que se considera arte, luego, obra de arte, y lo que se considera artesanía, luego arte popular, artesanías o manualidades.

Aunque los orígenes de esta diferenciación, como casi en todo desde una mirada occidental, están en Grecia (artes versus técnica), fue en el Renacimiento europeo donde esta división adquiere pleno sentido al configurar la diferencia de calidad productiva y de jerarquía social entre el artista y el artesano. Pero la articulación estructural que en buena medida perdura hasta el presente tiene lugar bajo el influjo las políticas ilustradas que, en consonancia con los modos de producción del capital y el sentido simbólico del valor (material y simbólico), fueron promovidas por algunas élites desde finales del siglo XVIII, tanto en Europa como en las colonias americanas. Esta articulación favoreció, como nos recuerda Aurora Fernández Polanco (2019, p. 94),

\footnotetext{
la radical separación entre las artes que muestran de forma meridiana la división del trabajo: por un lado, las Bellas Artes, donde se preparan las 'almas bellas' para mejor gloria y representación de las naciones; por otro, 'las artes aplicadas', desde donde se procuraba remontar la economía.
}

Un buen ejemplo de la asociación de lo artesanal con la economía se aprecia en el impulso que adquiere la formación de artesanos en habilidades artísticas en el siglo XVIII, que, en el caso español, se refleja en las propuestas de Jovellanos y, en particular Pedro Rodríguez Campomanes (1991), quien en 1774 


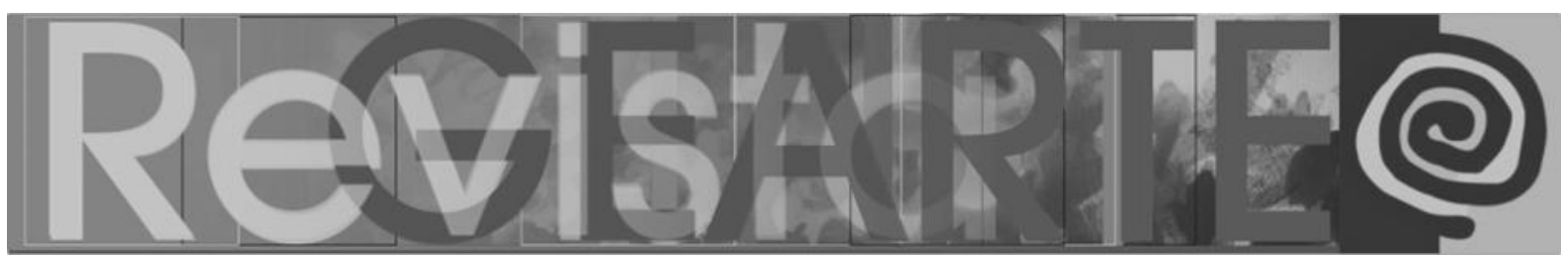

publicó Discurso sobre el fomento de la industria popular y al año siguiente, Educación popular de los artesanos. Un reflejo de esta valorización de las artes/artesanías podemos encontrarlo en los diseños que se realizan en Valencia para la producción de las sedas manufacturadas que forman parte de los ropajes y los tapizados de muebles y habitaciones y de su producción para exportarlas a las colonias en lugar de comprarlas en París o Londres.

Esta separación/relación entre arte-artesanía se ha mantenido hasta nuestros días con algunas excepciones, como el movimiento de Arts \& Crafts, que se genera en Gran Bretaña en el siglo XIX en torno a William Morris y que se expande por ciudades europeas y americanas. Hay que recordar que este movimiento aparece como reacción a la industrialización y a los inicios de la producción en serie, como un intento moral de recuperar el sentido de la producción artesanal frente a la mecanizada. Este movimiento refleja el rechazo y los miedos que genera la fábrica y la industrialización y que se proyecta en la recuperación de un arte gótico idealizado - de base artesanal - , que podemos encontrar en la obra de Gaudí y de otros arquitectos modernistas. Modernismo fue el nombre que recibió el Art Noveau en Cataluña, que rescata el valor de lo artesanal - y del artesano - en las diferentes facetas decorativas y constructivas de sus producciones.

En el pasado siglo, el ideal de la Bauhaus también recupera el sentido de lo artesanal y lo traslada en los proyectos arquitectónicos y en los diseños de objetos de uso diario. Sin embargo, estas reacciones que generaron brechas en el mundo de las bellas artes no fueron, como señala Bea Espejo (2020, s.p.), "lo suficientemente grande para un museo y un mercado atento siempre a aires nuevos". Por ello, estas reacciones que ponen en relación las artes y las artesanías, que tratan de entrecruzarlas se difuminan a partir de la segunda mitad del siglo pasado, por la propia configuración del sistema del arte. Como de nuevo apunta Bea Espejo (2020, s.p.) "Algunos veían en lo artesano la antítesis de lo mecánico, que por aquel entonces se había convertido en el estandarte de futuro. 


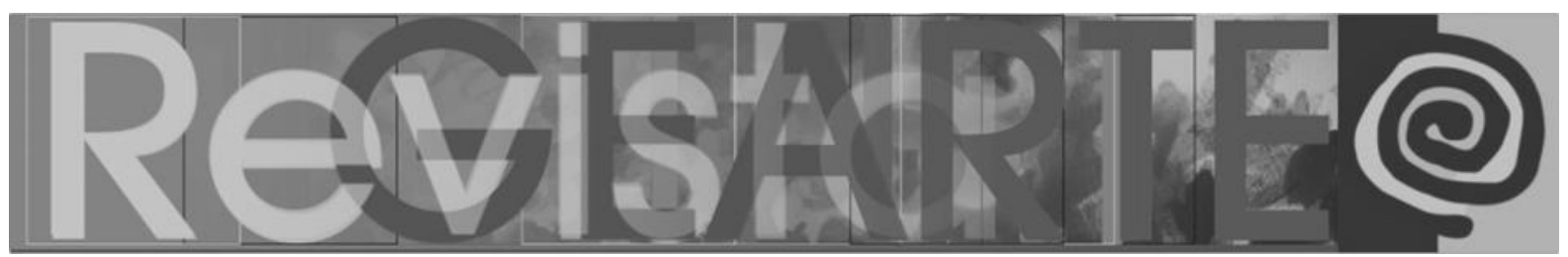

Un oficio anticuado al que se añadía el tinte de lo doméstico y lo femenino, que siempre andaba en penumbra mediática".

Sin embargo, a partir de la entrada en el presente milenio, comienza a dibujarse una nueva época, con una articulación entre arte/artesanía que tiene algunas singularidades que la diferencian de las acciones pretéritas. Ahora no se trata de un vínculo económico, o de un proyecto de regeneración estética de la sociedad. La dualidad artesanía y arte se diluye en la medida en que las prácticas artísticas toman lo artesanal, no como un apoyo del arte o como una manera de expandir el terreno de lo artístico. Se trata de un cambio en la onto-epistemología y praxis del arte. Lo que se pone en juego son acciones que pretenden, "no de establecer una Academia de las Artes que establezca una nueva unión entre dos mitades escindidas (artes bellas y oficios)", sino abordarlas, como propone Fernández Polanco (2019, p. 98), desde "una dinámica que repiense un proceso de reconversión estética, política, ecológica y epistémica" que para Bea Espejo (2020) supone una reivindicación de lo artesanal como una ideología artística que va más allá de los oficios. La artesanía vuelve a ocupar un lugar central en la práctica de muchos artistas que reivindican el manual como una nueva ideología más allá de la artesanía.

Nos permitimos plantear algunas hipótesis que propongan líneas de investigación para ayudar a comprender la emergencia de esta articulación de las artes como artesanía, o si se quiere de lo artesanal como artístico. En primer lugar, hay que señalar que este movimiento se manifiesta en una amplia presencia de mujeres. Lo que permite plantear el supuesto de que el rescate de lo artesanal como práctica artística se plantee como réplica a la vez irónica, militante y reivindicativa frente a esa larga tradición de exclusión de las mujeres de la centralidad del sistema del arte, recluyéndola en el ámbito doméstico. Ahora se revalorizan trayectorias ya existentes, como las de Françoise Grossen (1943), artista textil conocida por sus esculturas de cuerda trenzada; Sheila Hicks (1934), de cuya obra el Pompidou de París presentó una exposición en 2018; Anni Albers 


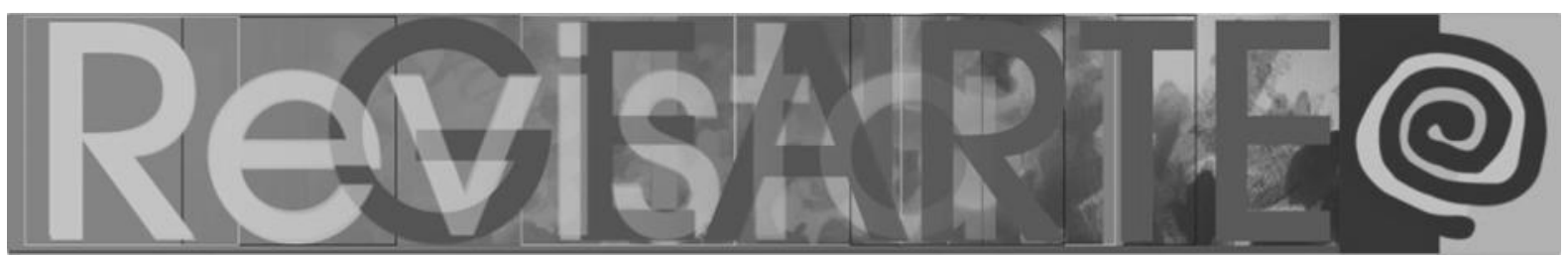

(1899-1994) de quien la Tate de Londres organizó una exposición en 2018-2019. Este centro de arte tiene pendiente una exposición de otra pionera, Magdalena Abakanowicz (1930-2017).

También hay que considerar a Ruth Asawa (1926-2013), cuyas esculturas inspiradas en la cestería de México son un referente de este puente al que nos referimos. Tres exposiciones muestran, cuando escribimos estas páginas, la vitalidad de esta propuesta: Making Knowing: Craft in Art, 1950-2019, en el Whitney Museum of Art de Nueva York (hasta finales de 2020 y donde la obra de Asawa es una de sus principales reclamos); la exposición con dos piezas de la mexicana Pia Camil (1980) titulada Velo Revelo en el Clark Art Institute de Williamstown (Estados Unidos, hasta el 3 de febrero de 2021) y Arts \& Crafts: Between Tradition, Discourse and Technologies en la Kestner Gesellschaft de Hannover (del 2 de octubre al 10 de enero de 2021). Además de estas artistas/artesanas también hay que resaltar a Rosemarie Trockel, Leonore Tawney, Eva Hesse, Grayson Perry.

En el segundo semestre de 2019 (del 17 de septiembre al 3 de noviembre) se celebró en Madrid la octava edición de la Bienal Internacional de Arte Textil Contemporáneo WTA, bajo el lema Ciudad Sostenible, que reunió a artistas de 75 nacionalidades, totalizando la presencia de 25 países de los cinco continentes en los distintos espacios de exposición. Entre ellos, la presencia de Judith Scott, Paloma Navares, Marisa González y Aurèlia Muñoz Ventura. En esta muestra, estaba exhibiendo su trabajo y fue una de las premiadas, la artista Lucia Loren, que en esta edición de la Revista GEARTE nos presenta parte de su producción, a través de uno de los Ensayos Visuales aquí contemplados. También en Madrid hubo la Exposición TraMares: un recorte de Textil Brasileño, en la Casa Brasil, país homenajeado por esta Bienal. En esta exposición participaron 21 artistas, como Zorávia Bettiol, Renata Meirelles, Marta Meyer, Veronica Filipak, Marina Godoy, Ilca Barcellos, entre otros. 


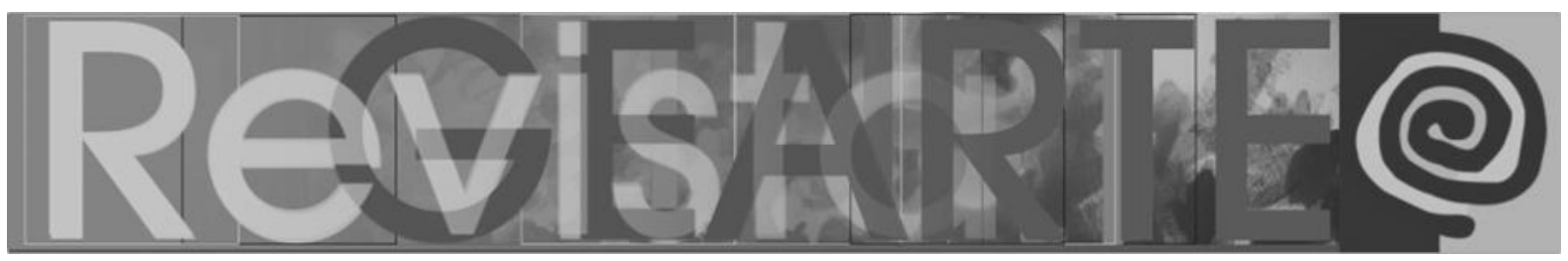

En Brasil tenemos una gran variedad de nombres que proponen esta fusión entre el arte y la artesanía, entre ellos la fuerte expresión de Lygia Clark, con sus obras sensoriales, cuyo proyecto político se desborda y lleva lo popular a un contexto artístico, sin separarlo ni dicotomizarlo. Adriana Varejão en las narrativas del azulejaria algunas hechas de los trozos de cerámica y los platos, remodelados y pintados; o aun Vera Chaves Barcellos, proponiendo sus paisajes epidérmicos; también la obra de Leda Catunda, que refleja superficies únicas y materiales no convencionales, en una poética que expande los límites de la pintura; o incluso la joven artista Yuli Yamagata, que transita entre composiciones, volúmenes, esculturas, artesanías y costuras, a través de la extrañeza de formas, entre tantos artistas.

En esta extensa lista también podemos incluir a Ernesto Neto, Mike Kelley, Jorge Pardo, Arthur Bispo do Rosário, Cildo Meireles, Tunga, Vik Muniz, José Leonilson, Alexandre Heberte, Hélio Oiticica, Denilson Baniwa, entre otros. Sin embargo, es un movimiento en el que las mujeres tienen un papel preponderante. Mujeres que forman parte de una nueva generación de artistas quienes, utilizando una variedad y fusión de formatos, como señala Bea Espejo (2020, s.p.), al tiempo que "disloca $(n)$ cualquier tipo de lógica cronológica". Donde la artesanía, al posibilitar una "acumulación desorganizada de elementos" que parecen "imitar la contradictoria función de la mente humana" como sucede con los jarrones de Milea Muzquiz (1927); o en cómo el arte/artesanía se proyecta como expresión de identidad cultural en un mundo globalizado en los trabajos de Azra Aksamija (1976) u Olaf Holzapfel (1969). Este recorrido esboza, que sobre todo entre las mujeres, se recupera la artesanía "de modo difuso, profuso y entrelazado", sino como un sentido del arte otro, que dibuja un relato sobre el arte y el artista que proyecta un lugar propio que se vincula con otras genealogías y rescata espacios de ser situados en los márgenes del sistema del arte.

Esta última referencia abre una segunda hipótesis, que puede confrontar la relación del arte/artesanía con una respuesta al desastre ecológico, en forma de lo 


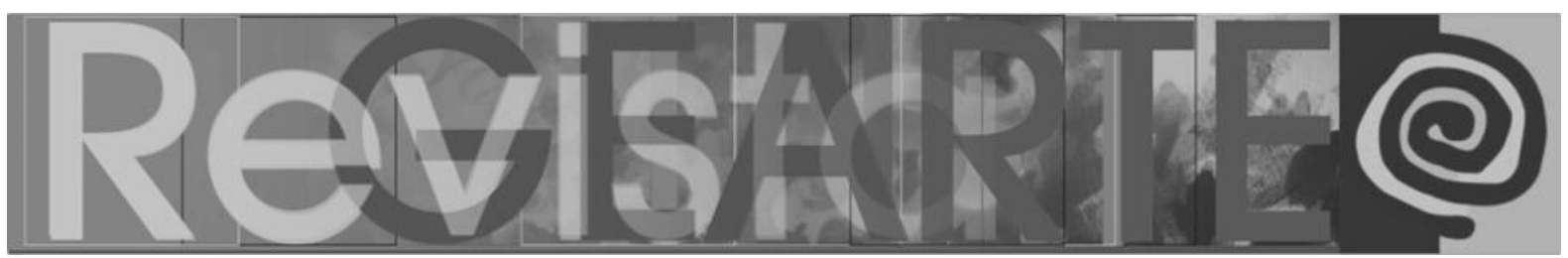

que Aurora Fernández Polanco (2019, p. 96) ve como una "reconversión" que trata "de retomar los 'oficios' del lado de la buena vida y no al servicio de la producción". Las propuestas de Pia Camil (1980) nos hablan de la descomposición del paisaje urbano mexicano al tiempo que plantea una crítica al consumismo. Sus textiles, como señala Bea Espejo (2020, s.p.) "siempre están en el límite de la rasgadura para cuestionar la fragilidad de lo que nos sostiene y lo que nos mantiene unidos". Algo que también plantea Josep Maynou (1980) cuando relaciona performance, textil, dibujo e instalaciones mediante un acercamiento a una amplia variedad de objetos de consumo populares y de prácticas sociales de la cultura popular. Con lo que de nuevo se abre la puerta hacia el cuestionamiento de la división y jerarquía entre alta y baja cultura.

La tercera hipótesis, se vincula a la llamada de atención que hace Bea Espejo (2000) y que nos recuerda que el sistema del arte, como parte del sistema capitalista, tiene la tendencia hacia la fagocitación y el aprovechamiento de todo lo que emerge como nuevo. Ese sistema tiene una larga experiencia en integrar cualquier movimiento que puede aparecer en las periferias o en los márgenes. Sobre todo si vislumbra alguna forma de rentabilidad. De aquí el toque de atención que esta autora nos deja:

Con el \#MeToo tras la oreja del museo y la reivindicación de los oficios entre la generación más joven de artistas, la artesanía abraza un estatus renovado en el mundo del arte. En los últimos años, ha pasado de ser una pieza de mal encaje a una vía de escape. Pocos campos están más revalorizados, incluso más allá de lo artístico. Es el negocio perfecto. El nuevo lujo. $Y$ hay porqués. En un momento de inquietud colectiva, el trabajo manual proporciona un ancla firme. Es minucioso, regular y preciso. Nos da algo en lo que creer. Lo complicado convertido en posibilidad. Un campo mental conocido y un tiempo pausado, consciente y genuino alejado de la habitual ansiedad de la vida contemporánea (ESPEJO, 2000, s.p.).

Todo lo anterior nos ayuda a situar las aportaciones del presente número de GEARTE en unas coordenadas más amplias que permiten intuir el calado del desplazamiento que acompaña al movimiento - entendido no en el sentido canónico de la historia del arte, sino como desplazamiento que posibilita otras 


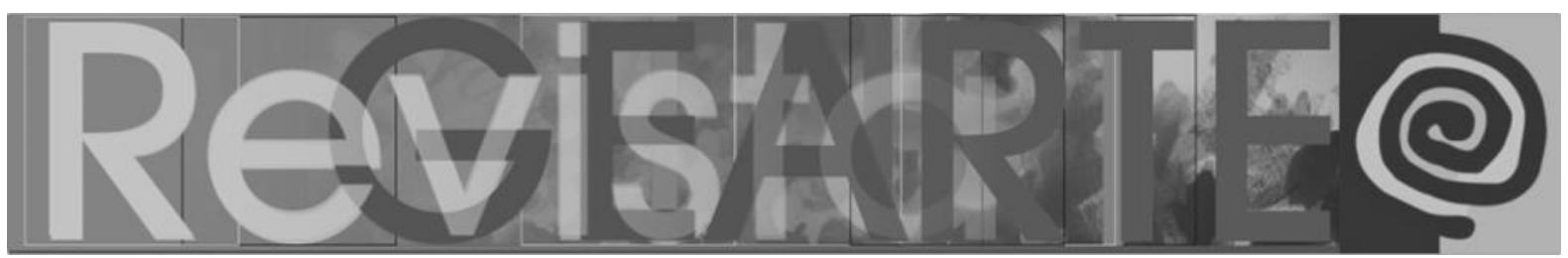

relaciones, miradas y encuentros - del arte/artesanía. Pero también la propuesta que aquí se abre quiere ser, como señala Silvia Rivera Cusicanqui (1986, p. 36) una alternativa a "la comunidad-mapa" (que suele ser la visión de los varones, más conceptual), mediante "la comunidad-tejido" (que tiende a ser visión de las mujeres) para que se genere "una nueva praxis de producción y circulación de saberes prácticos y productivos tanto como éticos y organizativos", desplazamiento que también puede afectar a cómo se plantean y orientan artes en la educación.

\section{El arte/artesanía y la ampliación de espacios para la educación a través de las artes}

Una de las funciones sociales de las artes en la educación (en un sentido amplio, y no solo en la Escuela) ha sido la de transmitir y perpetuar los dualismos y jerarquías señalados en la primera parte de este artículo. Conocer y valorar a los artistas (hombres blancos y occidentales) del canon que se ha tejido en el relato dominante de la historia del arte ha sido su función primordial tanto en los referentes que se exhiben en los museos y centros de arte, como los que aparecen en los libros didácticos o en las propuestas que se llevan a cabo en los talleres de arte. El aprendizaje y valoración de las producciones relacionadas con las bellas artes occidentales ha sido - y sigue siendo - la tónica dominante. Lo que ha llevado - sigue llevando - a la exclusión de lo que no forma parte de este acervo. Lo que supone dejar de lado, o reducirlo a lo anecdótico y circunstancial, todo aquello que esté en los márgenes de esa corriente poderosa y dominante.

En los casos en que lo periférico ocupa alguna forma de centralidad es porque puede ser reconocido dentro del sistema hegemónico (se han formado o reside en ciudades occidentales $u$ occidentalizadas o se reconoce en su obra reflejos de las categorías artísticas de la historia del arte occidencial) o confirman las visiones geoestratégicas de los occidentales. Incluso en organizaciones de arte-educación a las que se les supone un carácter inclusivo como InSEA, hasta fechas recientes sorprendía cuando los pocos colegas africanos que asistían a sus 


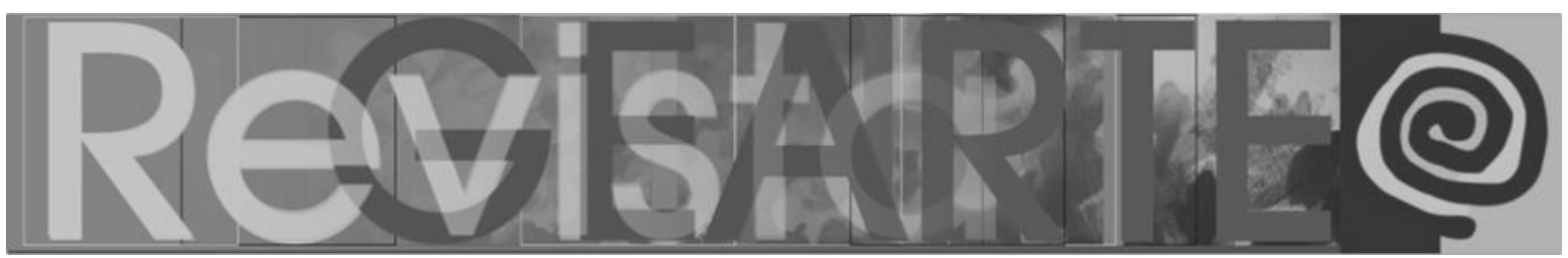

encuentros reivindicaban la artesanía como su forma genuina de arte-educación, en la medida que, su sentido simbólico, les vinculaba con los relatos que les constituían frente a las prácticas colonizadoras. Esa relación entre la artesanía y su sentido simbólico es algo que se excluye cuando se vincula sin matices lo artesano con los trabajos manuales, como experiencia de educación artística.

El tema - la problemática - del papel de las artes en la educación como perpetuadora de dualismos y transmisora de formas de exclusión sería una cuestión para explorarla con amplitud en un artículo o en una monografía. Aquí la dejamos enunciada como señal de alerta de lo que (nos) estamos privando cuando - como ya sucede en occidente - desplazamos el acceso a lo simbólico y a la imaginación - que es lo que nos constituye como señala Juan Arnau (2020) en su Historia de la imaginación - pero también para reivindicar y no olvidar, como señala Richard Sennett (2009) que la artesanía vincula la "cultura material" y el "conocimiento tácito", que son bienes de "capital social", esto es, conocimiento y habilidades que se acumulan y se transmiten a través de la interacción social. Todo lo cual constituye un saber corporal del que parece que en la actualidad en los países occidentalizados no se tiene demasiada conciencia. Pero además, plantear la presencia del arte/artesanía en la educación, nos recuerda, cómo hace Sennett (2009), que la motivación básica del artesano es lograr un trabajo bien hecho por la simple satisfacción de conseguirlo, rescata una relación con lo material que redefine el sentido de la relación entre lo humano y lo no humano, y que puede abrir líneas de escape, como sigue señalando Sennett (2009), ante a la degradación de la conciencia de sí mismo y de la autoestima a la que conducen las actuales formas de producción capitalista.

\section{La propuesta del monográfico}

Como ya hemos señalado, en la edición de la Revista GEARTE que ahora presentamos al público, se hace referencia a un tema importante en el contexto artístico, principalmente en el sentido de legitimar (sin eximirse del debate) las 


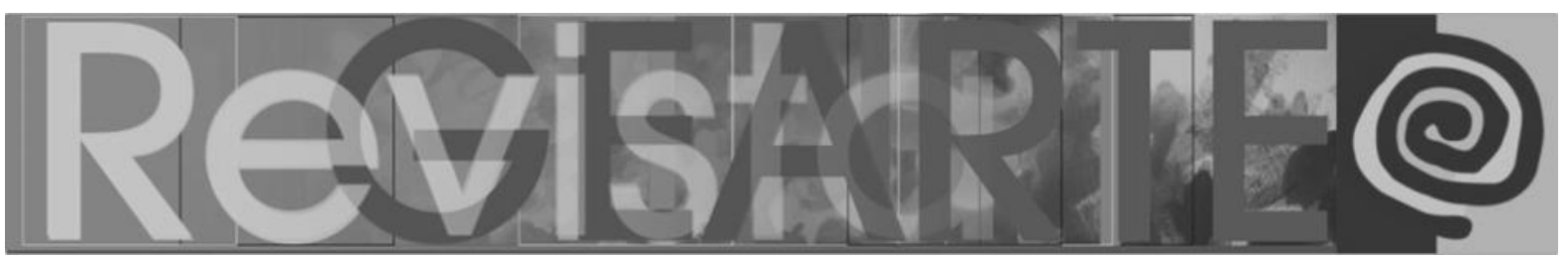

manifestaciones artesanales más allá de las dicotomías que se han establecido históricamente entre el arte y la artesanía.

Así, planteando la discusión y avanzando propuestas que se establecen bajo la premisa "La enseñanza de las artes visuales y la artesanía: experiencias y confluencias metodológicas" se presenta, en su ámbito, la intención de promover diálogos entre las investigaciones, reflexiones y experiencias relacionadas con las artes visuales, su enseñanza y sus interfases con los oficios, para situar el campo de investigación que proponen estos planteamientos artísticos, delimitando territorios sin, no obstante, establecer fronteras. En este sentido, propone (re) pensar en nuevas formas de apuntar, explorar las posibilidades de expandir los límites y establecer conexiones que permitan situar el quehacer artesanal - sus proponentes, los procesos de reflexión y sus resultados - en un contexto más amplio de discusiones. Esto significa aclarar la necesidad de fomentar las actitudes que exigen conectar e integrar este conocimiento y hacerlo con la vida de cada individuo.

Las analogías de la vida como tejido han sido metáforas de uso recurrente, narraciones que forman parte de un imaginario colectivo, pensadas a partir de las tramas que se construyen en la vida cotidiana, de los hilos - los días - tejidos en la urdimbre del tiempo, en las puntadas hechas y deshechas, por los deseos y aspiraciones humanas, en las costuras o bordados, en definitiva, en un universo ilimitado de relaciones. Como dijo Guimarães Rosa: "viver é um rasgar-se e remendar-se" (1968, p. 76), porque este tejido que es la vida tiene la condición de ser cosido, de regenerarse - aunque, al final de esta trayectoria, puede presentar las marcas de las "rasgaduras y manchas" a las que fue sometido y que están circunscritas en él. De este mismo universo parecen surgir las cinco pieles descritas por el artista austriaco Hundertwasser (1928-2000), que tan bien integra y conecta, a través del arte, al ser humano con la vida y la naturaleza. 


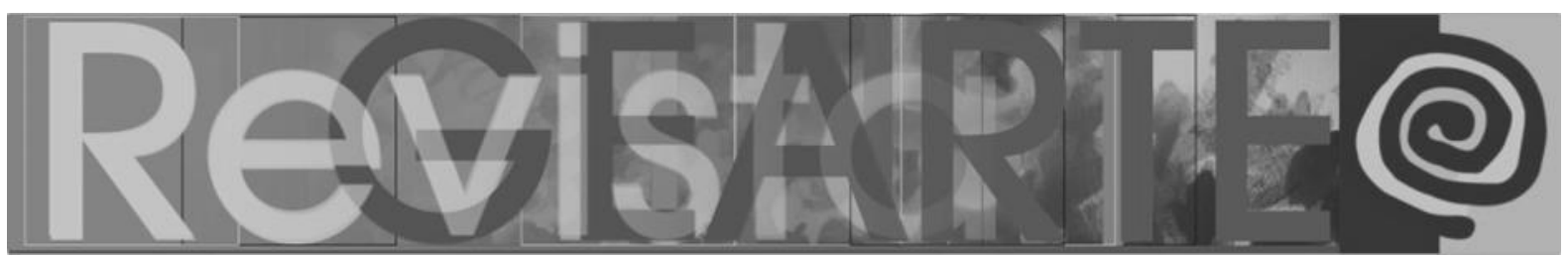

A partir de verbos como tejer, dar forma, fusionar, coser, forjar, entre muchos, reivindicados por el trabajo con las manos y la cabeza (SENNETT, 2009), la artesanía se concibe y gana en materialidad, como una actividad original que pretende promover las relaciones dialógicas con la vida misma. Tales diálogos pueden tener lugar de manera solitaria, es decir, sólo entre el sujeto y el objeto de su hacer. Sin embargo, en muchas situaciones, se producen de manera solidaria, construyéndose en acciones interactivas y comunitarias entre los sujetos y sus hechos, ya que el trabajo colectivo es la marca que, de alguna manera, constituye el trabajo artesanal en la contemporaneidad. Son colectivas - y la mayoría de las veces femeninas -, como ya hemos apuntado, estas artes de bordado, tejido, crochet y tantos otros oficios y manualidades como nuestra imaginación pueda nombrar.

\section{El contenido del monográfico}

Este artículo que presenta la Revista Gearte, además de proponer elementos para pensar y discutir las experiencias, confluencias y derivas en torno al arte y la artesanía, aporta un audiovisual producido para una actividad que relaciona estos conceptos con las cuestiones identitarias, a partir de la exposición "Teixint Identitats", cuyo texto curatorial, de Carmen Marcos y Ascensión García, también se presenta en este volumen. El proyecto, titulado "Artesaneando Identidades", que tuvo lugar en el primer semestre de 2020 con más de 70 alumnos de la Educación Secundaria Obligatoria de la Escuela Oriol Martorell (Barcelona), tuvo como propuesta final un video producido por Jesús-Ángel Prieto, profesor de historia y teoría del arte de la Escola Massana de la Universitat Autònoma de Barcelona, que presentamos aquí (https://vimeo.com/480983805) a partir de algunas declaraciones explicativas de su productor:

Hacer es pensar (SENNETT, 2009), y ese pensar haciendo, se constituye en una relación intensa entre la mano y el cerebro. $Y$ ahí no hay jerarquías, la mano enseña al cerebro y este le devuelve sabiduría y reflexión. Fue siglos más tarde 


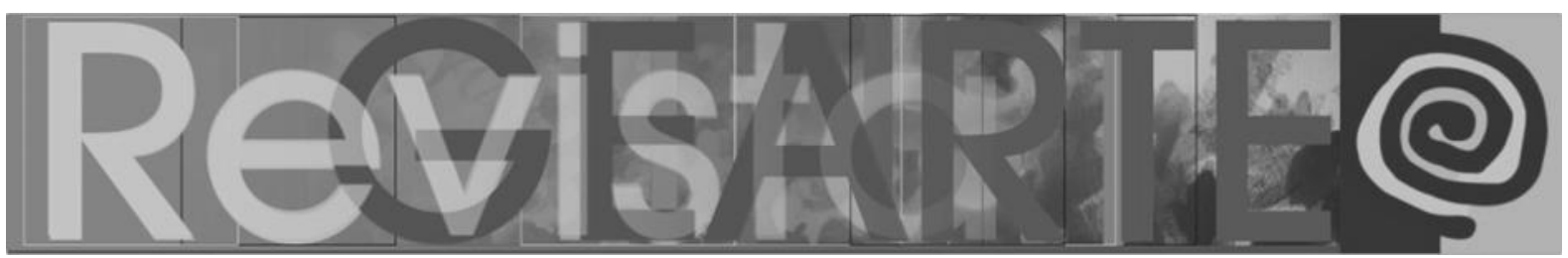

que el pensar se convirtió jerárquicamente en más poderoso, y no digamos ein nuestra época donde la tecnociencia se ha convertido en la nueva religión, y la voluntad de superarse como seres humanos nos lleva a considerar el robot como nuestra más excelente creación. Dejaremos de hacer, esa es la panacea..., antropológicamente dejaremos de pensar. $Y$ abandonaremos las manos y con ellas la materia, y ya no estaremos en el mundo...Pero el mundo es materia, materia que se agota, materia finita que nos recuerda los límites ecológicos. La artesanía es nuestra revolución, nuestro camino hacia esa conciencia de especie que nos haga ser "buenos artesanos del medio ambiente".

A esta y otras cuestiones nos invita a debatir y ampliar la presente reflexión, cuya propuesta abre una vía de acercamiento al arte y la artesanía y no sólo para presentar aspectos sobre el arte o la artesanía, aunque es importante subrayar que, en este debate, a menudo sigue existiendo la idea equivocada que persiste en la defensa de la artesanía aislada del arte, a raíz de las dicotomías históricas ya señaladas.

Dentro de este volumen de la Revista GEARTE, el artículo titulado "Trabajo artesanal, artesanía e industrias creativas: reflexiones sobre las transformaciones de la actividad sociocultural", de Daniel Roberto Vega Torres, profesor de la Fundación Universitaria Juan de Castellanos (Tunja/Boyacá, Colombia), aporta una crítica a la comprensión de la artesanía y el trabajo artesanal desde el histórico desarrollo capitalista. Sus reflexiones contemplan la industria y la artesanía, entendiendo las relaciones sociales, políticas y simbólicas que ofrecen el reconocimiento del surgimiento de la artesanía y del artesano como una expresión cultural. Las reflexiones conceptuales y políticas definen las trayectorias de estudio e intervención propuestas por el autor.

En el texto de Ana Paula Aparecida Caixeta, profesora de la Universidade de Brasília (Brasília/DF, Brasil), y Luiz Carlos Pinheiro Ferreira, profesor de la Universidade de Brasília (Brasília/DF, Brasil), bajo el título "Artesanía como 


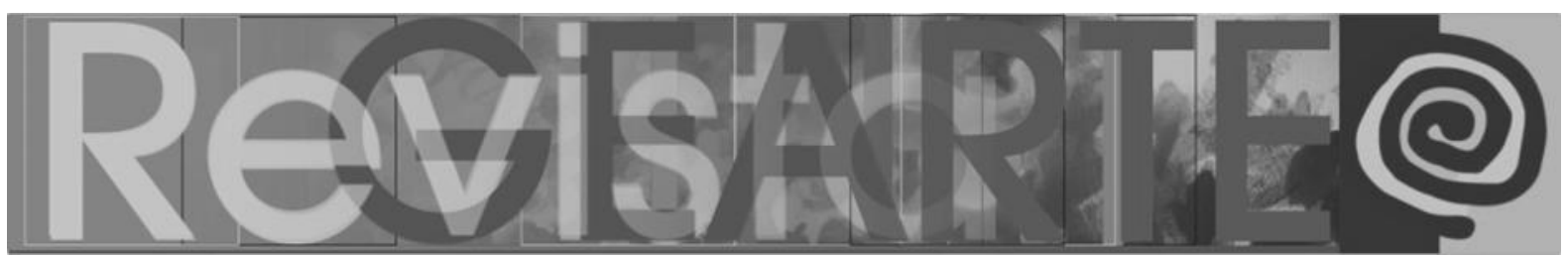

proceso: el estado curricular en las Artes Visuales como espacio de observación y reflexión", se presentan diálogos sobre la pasantía curricular en el campo de la observación y la regencia en las Artes Visuales. En él, aborda temas que han pasado por la formación diaria en este grado, que construyen reflexiones que pasaron por esa estancia y promovieron interfaces con la artesanía, incluyendo discusiones de un conocimiento sensible que piensa en la artesanía como un proceso.

María José Delgado Corredera, profesora de la Universidad de Málaga (Málaga, España), propone una experiencia a partir de sus escritos "Artesanía como forma de supervivencia. Una historia de vida en la posguerra española". En ellos, señala que la artesanía implica la desconexión de la vida exterior y la liberación de la imaginación, favoreciendo un diálogo interno y reflexivo para la búsqueda personal. Las historias de vida, entrelazadas con la artesanía, encuentran un significado educativo en ambas. Cómo se construye una identidad y cómo la artesanía puede ser experimentada como algo habitual que se aprende y tiene la capacidad de proporcionar supervivencia. Desde el presente, la protagonista Electra comprende su pasado y reflexiona sobre él.

En "Bordaduras en la experiencia formativa de mujeres campesinas" de Jossier Sales Boleão, doctorando de la Universidade Federal de Goiás (Goiânia/GO, Brasil), y Alice Fátima Martins, profesora de la Universidade Federal de Goiás (Goiânia/GO, Brasil), tenemos una experiencia desarrollada con mujeres campesinas en talleres de arpilleras, que configura procesos de transformación en la forma en que estas mujeres ven sus realidades y se conectan con la realidad de los demás. A través del bordado libre, las posibilidades de diálogo se tejen en objetos artísticos y más allá, que emergen del individuo al colectivo y se cosen desde el colectivo para resignificar al individuo, en total relación con la vida cotidiana que da luz a los recuerdos y afectos entre las manos campesinas. 


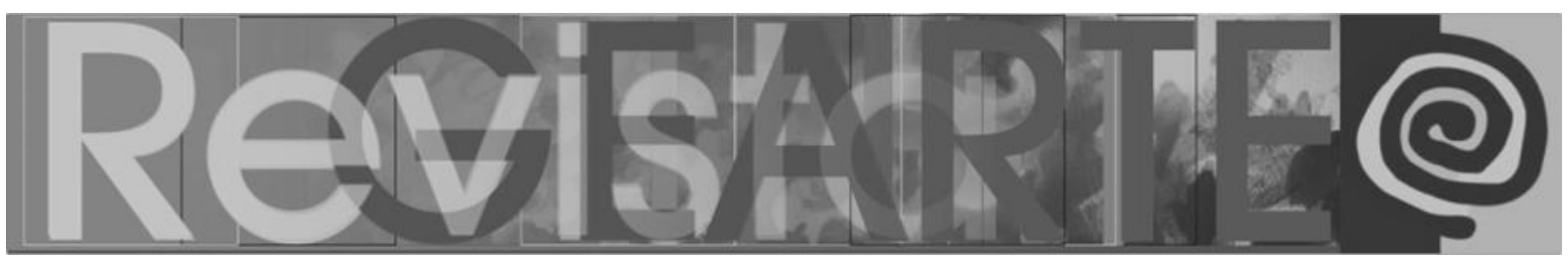

Los debates y contenidos propuestos en el artículo de Tales Bedeschi Faria, profesor del Instituto Federal de Educação, Ciência e Tecnologia de Minas Gerais (Santa Luzia/MG, Brasil), y Vanginei Leite Silva, estudiante de maestría de la Universidade Federal de Minas Gerais (Belo Horizonte/MG, Brasil), bajo el título "Las artes del pueblo Xakriabá y la escuela monoepistémica: desafíos metodológicos" cuestionan que, doce años después de la promulgación de la Ley № 11.645/2008, hay pruebas de que la enseñanza de las historias y culturas de los pueblos indígenas del Brasil no se ha llevado a cabo en las escuelas. ¿Cómo puede la escuela pedirle al maestro que enseñe una historia y una cultura que nunca ha aprendido? A partir de un diálogo entre un maestro del pueblo Xakriabá y un maestro no indígena, se discuten puntos fundamentales, como las concepciones del arte, la cultura y la educación, entre los Xakriabá, y cómo estas personas enseñan y aprenden sus artes.

Bajo el título "Tejiendo identidades. Un diálogo entre arte y artesanía" de las autoras Carmen Marcos Martínez, profesora de la Universitat Politècnica de València (València, España) y Ascensión García, profesora de la Universitat de Barcelona (Barcelona, España), el artículo presenta la exposición Teixint Identitats (Barcelona/ES), que pretendía difundir una forma concreta de hacer arte reuniendo a un grupo de treinta y un artistas para compartir el uso de técnicas artesanales cercanas al textil. Tanto el contenido conceptual como las técnicas utilizadas presentan cierta diversidad, explorando cuestiones relacionadas con el género, la identidad, el entorno doméstico o personal, así como cuestiones sociales y ambientales dentro de esta exposición de arte.

En la comunidad de Sibauma, los hermanos maestros del coco de zambê, del grupo Herdeiros de Zumbi, hacen posible la recuperación de este arte que sólo existe en Rio Grande do Norte (Brasil). De las manos talentosas emergen tambores, berimbaus y otros instrumentos usados en las rodas de coco y capoeira. En la artesanía necesaria para fabricar cada instrumento, la combinación de los conocimientos y las materias primas locales con los productos del comercio 


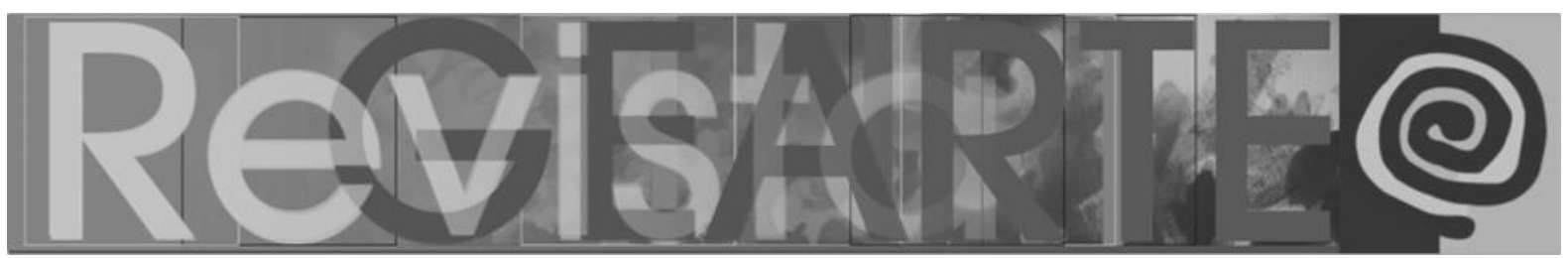

popular permite que el coco de zambê exista, se renueve y resista. Este es el contenido del artículo de Nilton Xavier Bezerra, profesor del Instituto Federal de Educação, Ciência e Tecnologia do Rio Grande do Norte (Mossoró/RN, Brasil), titulado "Procesos y reminiscencias culturales en la producción artesanal de instrumentos de coco de zambê en Sibaúma/RN".

Lurdi Blauth, profesora de la Universidade Feevale (Novo Hamburgo/RS, Brasil), y Amanda Becker, estudiante de maestría de la Universidade Feevale (Novo Hamburgo/RS, Brasil), nos presentan "Imágenes híbridas: intersecciones de la fotografía con medios litográficos alternativos", a partir de paseos por el flujo de la vida cotidiana, las imágenes se transforman y se resignifican, adquiriendo otra grandeza, valorada por una mirada sensible a la naturaleza. Una producción de paisajes llamada "Inços", realizada desde la fotografía digital y de medios analógicos alternativos, trata de sustituir los materiales utilizados tradicionalmente en la litografía. Presenta algunos de los resultados obtenidos por la grabación con cola de soda de las planchas offset descartadas por la industria gráfica y sus posibilidades de reproducción de imágenes.

Todavía tenemos, en esta edición de la Revista GEARTE, dos ensayos visuales: el primero titulado "Tres performances para un país que lucha con el arte", donde Ricard Huerta, profesor de la Universitat de València (València, España), presenta un ensayo visual de tres performances, en las que los artistas intérpretes o ejecutantes interactuaron con la gente en el espacio público. Estas acciones tuvieron lugar durante el "Il Seminario Internacional sobre Arte / Género / Enseñanza en Tiempos de Conservadurismo", celebrado en el Centro de Artes de la Universidad Regional de Cariri — URCA (Crato, Brasil).

Y por fin, presentamos la propuesta de Lucía Loren Atienza, profesora de la Universidad Nebrija y del Instituto Nebrija de Competencias Profesionales (Madrid, España), titulada "Hacia una cultura material cíclica desde el arte y la artesanía", en la que la artista aporta un recorrido en imágenes, desde su contexto de 


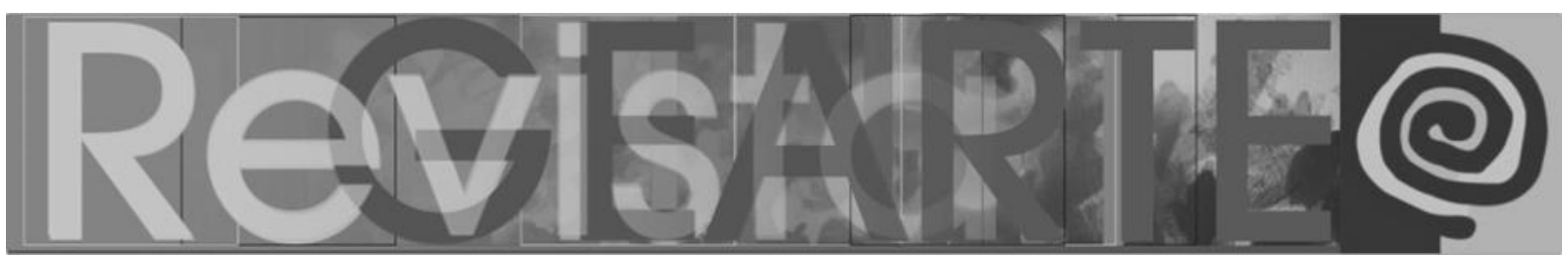

investigación para desarrollar su producción artística, que parte del lugar y de los materiales que lo rodean, para comprender las transformaciones del diseño del paisaje. Sus intervenciones se mueven entre el arte y la artesanía, creando diálogos que buscan la revalorización de una cultura material cíclica, a partir de los recursos del propio territorio, sin generar residuos ajenos.

Nos gustaría dar las gracias a todos los que enviaron artículos para componer este tema, los revisores y el artista y profesora Dra. Umbelina Barreto para la portada hermosa.

Esperamos que, por lo que hemos señalado, este número de la Revista GEARTE pueda abrir espacio y permitir al lector algunos desafíos para mirar estas experiencias, confluencias y derivas desde otros puntos de vista, buscando medios alternativos factibles de diálogo a través de la enseñanza de las artes visuales desde la artesania y de la artesania fusionada en las artes visuais.

\section{Referencias}

ARNAU, Juan. Historia de la imaginación: del Antiguo Egipto al sueño de la ciencia. Barcelona: Planeta, 2020.

ESPEJO, Bea. Aire popular. La artesanía vuelve a ocupar un lugar central en la práctica de muchos artistas que reivindican lo manual como una nueva ideología más allá de los oficios. Babelia, El País, 8 agosto de 2020. Disponible en: <https://elpais.com/cultura/2020/08/03/bab elia/1596456276_484106.html?prm=enviar_email > Acceso en: 5 set. 2020.

FERNÁNDEZ POLANCO, Aurora. Crítica visual del saber solitário. Bilbao: Consonni, 2019.

FREITAG, Vanessa. Reseña del libro La invención del arte: una historia cultural, de Larry Shiner. Alteridades, Ciudad de México, v. 25, n. 49 (jan.-jun. 2015): 129-133. Disponible en: <https://alteridades.izt.uam.mx/index.php/Alte/article/view/792>. Acceso en: 10 set. 2020.

SENNETT, Richard. El artesano. Barcelona: Anagrama, 2009.

RIVERA CUSIVANTE, Silvia. Oprimidos pero no vencidos: luchas del campesinado aymara y qhechwa de Bolivia, 1900-1980. Ginebra: Instituto de Investigaciones de las Naciones Unidas para el Desarrollo Social, 1986.

RODRÍGUEZ CAMPOMANES, Pedro. El fomento de la industria popular: la educación popular de Ios artesanos. Oviedo: Grupo Editorial Asturiano, 1991.

ROSA, João Guimarães. Sagarana. Rio de Janeiro: Livraria José Olympio, 1968.

SHINER, Larry. La invención del arte: una historia cultural. Barcelona: Editorial Planeta, 2004. 


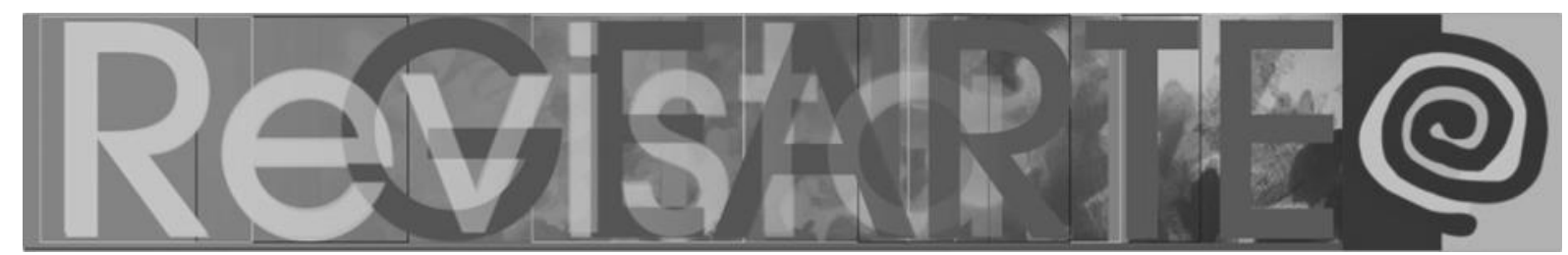

Dra. Rita Inês Petrykowski Peixe ${ }^{1}$

(Instituto Federal de Santa Catarina — IFSC, Itajaí/SC, Brasil)

\author{
Dr. Fernando Hernández-Hernández ${ }^{2}$ \\ (Universitat de Barcelona - UB, Barcelona/España)
}

Dr. Jesús-Àngel Prieto Villanueva ${ }^{3}$
(Escola Massana, Universitat Autónoma de Barcelona - UAB, Barcelona,
España)

Ma. Rosangela Canônica ${ }^{4}$

(Instituto Federal de Santa Catarina — IFSC, Itajaí/SC, Brasil)

Organizadores de esta edición

1 Doctora en Educación por la Universidade Federal do Rio Grande do Sul (UFRGS / Porto Alegre). Maestría en Educación. Especialista en educación artística. Licenciada en Educación Artística-titulación en artes plásticas y en Pedagogía-titulación en Orientación Educativa. Realizó pasantía posdoctoral en la Universitat de Barcelona. Profesora del Instituto Federal de Santa Catarina - IFSC, Campus de Itajaí. Investigadora del Grupo de Pesquisa em Educação e Arte (GEARTE / UFRGS) y coordinadora del Grupo de Investigação em Estudos de Imagem, Design, Artesania y Práticas Educativas (DZART / IFSC). Tiene experiencia en docencia, investigación y extensión con énfasis en: métodos y técnicas de enseñanza, estudios culturales y cultura visual, enseñanza de arte, formación docente, diseño social, economía solidaria y artesanía. Email: ritapeixe@hotmail.com

2 Es profesor doctor de la Unidad de Pedagogías Culturales en la Facultad de Bellas Artes de la Universidad de Barcelona. Miembro de REUNID, del grupo de investigación consolidado Esbrina y del grupo de innovación docente Indaga't. Lleva a cabo proyectos vinculados a la investigación basada en las artes, el giro postcualitativo, los nuevos materialismos, y la aproximación a las cartografías como epistemología y metodología. Autor de numerosos libros ya traducidos en Brasil. E-mail: fdohernandez@ub.edu

3 Es licenciado en Historia del Arte (1977) por la Universidad Autónoma de Barcelona, y Doctor (2017) por la Universidad de Barcelona, con la tesis "La lucha por el reconocimiento de los oficios artísticos y la Escola Massana de Barcelona. El caso de los esmaltes, la cerámica y la joyería". Ha impartido clases en la Escola Massana, Centro de arte y diseño de Barcelona (adscrito a al Universidad Autónoma de Barcelona) desde el año 1979, ejerciendo de coordinador director de este centro durante el período 1993-2000. Así mismo instauró y coordinó el Postgrado en Artes Aplicadas Contemporáneas (2014-19). Ha presidido el A FAD (Artistas y artesanos del Fomento de las Artes y el Diseño) durante el periodo 2003-07. Promovió y coordinó las jornadas sobre artesanía contemporánea IBERIONA (2003 al 2009), así como ha participado en consejos asesores a diferentes gobiernos en el ámbito de la artesanía y el diseño, y escrito artículos e impartido conferencias en estas materias. www.jesusangelprieto.eu E-mail: jesusangel.prieto@escolamassana.cat 
4 Máster en Diseño, con énfasis en Producción de Diseño y Contexto Sociocultural (UNIVILLE, 2013). Licenciada en Diseño de Producto (UNIVILLE, 2004). Tiene experiencia profesional en Diseño Social, habiendo trabajado en proyectos de Generación de Empleo e Ingresos dirigidos al emprendimiento popular. A través de la metodología social en el diseño, capacitó comunidades creativas, enfatizando procesos participativos para el desarrollo de productos. Actualmente forma parte del Grupo de Investigação em Estudos de Imagem, Design, Artesania y Práticas Educativas (DZART / IFSC), buscando investigar las posibilidades metodológicas del diseño y su uso en los procesos artesanales. Tiene experiencia en procesos artesanales en los contextos de la alimentación, la agricultura familiar y el sistema penitenciario, trabajando con Educación Popular, Género y Economía Solidaria, principalmente en los siguientes temas: Emprendimiento, Protagonismo Social, Autogestión Creativa, Estética, Desarrollo de Producto y Gestión Productiva. E-mail: canonicarosangela@gmail.com 